\title{
ADVANCES IN PROSTHODONTIC BIOMATERIALS
}

\author{
Dr. P. S. Manoharan, Dr. Balaji J
}

\begin{abstract}
Prosthodontics is a specialty that involves the replacement and restoration of lost dental structures with artificial substitutes. Many biomaterials have been developed to satisfy the demands laid by the functional, esthetic requirements of the stomato-gnathic system. The considerable advancements in this particular field, have often left the practicing dentist perplexed with regards to the correct choice. This paper provides an overview of the key recent advancements and milestones in biomaterial science in prosthodontics
\end{abstract}

Key words: Prosthodontic biomaterials, impression materials, Ceramics, Implants, silicones.

\section{Introduction}

Biomaterials used in the field of prosthodontia are those used for the replacement of the lost dentition. Of the plethora of Prosthodontic biomaterials available, the clinician is often puzzled with the choice of an appropriate biomaterial because of lack of sound scientific rationale and thorough knowledge and understanding of these materials. Most commonly, the clinician is guided by hearsay knowledge of the use of materials from other clinicians and medical representatives. Evidence based practices should be encouraged to gain confidence in the use of dental biomaterials by any dental practitioner.

Advances are aimed at improving the existing materials and to welcome new materials, so that the final restoration is made biocompatible and survive in the oral environment for considerable period of time. It is important to be aware of the current trend of dental practices and recent advancements of materials so that the dentist and the patient would be benefitted.

Biomaterial can be understood as any biologic or synthetic substance that can be introduced into body tissue as part of an implanted medical device or used to replace an organ, bodily function, etc. The following discussion will be based on the various commonly encountered biomaterials with their state of art and recent updates.

\section{Laboratory Materials}

\section{Denture Base Resins}

\section{Flexible denture base material}

These materials evolved as a result of dentist satisfying the patient's need for a softer clasp and ease of insertion. This material (polyamide) is considered to be ideal for partial dentures. The resin is a biocompatible nylon thermoplastic. Its unique physical and aesthetic properties provide unlimited design versatility and eliminates the concern about acrylic allergies. ${ }^{[1]}$ The denture is thin and lightweight and flexible enough to enter below the undercuts. But it is unbreakable and does not stain easily. It is comfortable to the patient as no tooth or tissue preparation is needed. The denture is esthetically very pleasing.

\section{Microwave Cured Denture Base Resin}

This resin is manipulated similar to conventional resins up to the point of curing. The microwave makes curing easier than conventional methods.

${ }^{*}$ Dr. P. S. Manoharan, Prof and Head, *Dr. Balaji. J, Sr. Lecturer, Department of Prosthodontics and Crown \& Bridge, Indira Gandhi Intitute Dental Sciences, Sri Balaji Vidyapeeth, Puducherry 607402, India. 
Three minutes and a standard 500 watt microwave are needed to cure higher quality and more precise dentures. This process saves time, while increasing the accuracy and strength of denture bases. Source of the activator is the heat generated by the colliding molecules which moves or vibrates around their axis. $[2,3]$

\section{Ultra high impact heat-cured denture base resins}

These resins evolved with the demand for high impact strength for the denture base material. These materials incorporate reinforcing materials and a curing temperature range that render them to be superior in their physical properties. These resins are claimed to be easily finished and polished, offer accurate fit and require at least 2 hours for heat polymerization. ${ }^{[4,5]}$

\section{Glass fiber reinforced denture base resins}

Several types of fibers, including carbon, aramid, woven polyethylene and glass fibers, have been used to strengthen denture base resins. Carbon and aramid fibers strengthened the resin but caused clinical problems, such as difficulty in polishing and poor aesthetics. Woven polyethylene fibers are more aesthetic, but the process of etching, preparing, and positioning layers of woven fibers may be impractical for the dental office. Silanated glass fibers are the fibers of choice for reinforcing denture base polymers. Improvement in flexural properties and fatigue resistance are seen with the use of glass fibers. ${ }^{[6-9]}$

\section{Denture Teeth}

\section{Composite Denture Teeth}

Micro filled denture teeth and Nano-filled denture teeth are available. Knoop hardness values (KHN) ranged from 28.2 to 29.8 for micro-filled composite, 18.9 to 21.6 for cross-linked acrylic, 22.7 for nano-composite, and 18.6 for conventional acrylic teeth. All micro-filled composite teeth were significantly harder than other teeth. The wear depth values were $90.5 \mu \mathrm{m}$ for the nano-composite, 69.8 to $93.0 \mu \mathrm{m}$ for the micro-filled composite, 80.8 to $104.0 \mu \mathrm{m}$ for the cross-linked acrylic, and $162.5 \mu \mathrm{m}$ for conventional acrylic teeth. The nano-composite tooth was harder and more wear resistant than the acrylic teeth but not significantly different from most of the cross-linked and micro-filled composite teeth. [10]

\section{Titanium and its Alloys}

Titanium is the most popular and commonly used among the metallic biomaterials in the field of medicine and dentistry. Titanium and its alloys are getting much attention for biomedical applications because of excellent biocompatibility, light weight, excellent balance of mechanical properties and corrosion resistance. Pure titanium and alpha + beta type titanium alloys including the Ti-6Al-4V, were originally designed for use as general structural materials, especially for aerospace structures, and only later adopted for biomedical applications. However, the toxicity of the beta-stabilizing element Vanadium was later pointed out. Therefore $\mathrm{V}$ in the Ti-6Al- $4 \mathrm{~V}$ has been replaced by other betastabilizing elements $\mathrm{Fe}$ or $\mathrm{Nb}$, both of which are considered to be safer for the living body

Low-modulus beta-type titanium alloys composed of nontoxic and non-allergic elements, such as $\mathrm{Ti}-29 \mathrm{Nb}-13 \mathrm{Ta}-4.6$ have been developed for medical and dental applications. The low modulus of this alloy effectively accelerates the healing of bone fracture and re-growth of bone. This type of alloy is also expected to be used in dental implants as well as in fixed dental prostheses such as crowns, inlays, bridges, and dentures. Very recently, nickel free shape-memory and/or super elastic betatype titanium have been developed for biomedical applications.

\section{Casting titanium}

Titanium has a high melting point $\left(1660^{\circ} \mathrm{c}\right)$ and is melted using electric plasma arc or inductive heating in a melting chamber filled with inert gas or held in a vacuum. The molten metal then is transferred to the refractory mold via centrifugal or pressurevacuum filling. ${ }^{[1]}$

\section{Machining titanium}

Dental implants generally are machined from billet stock of pure metal or alloy. Dental crowns and bridge frameworks also can be machined from solid metal stock via computer-aided machining. Another method for fabricating dental appliances is electric discharge machining, which uses a fabricated 
graphite die to erode the metal to final shape via spark erosion. ${ }^{[12-14]}$

\section{Waxes}

\section{Light curing waxes}

The wax patterns of the metallic frameworks of the removable partial dentures could be made directly on the cast, using profiled waxes like: $\mathrm{Ti}^{-}$ Light or LiWa (light curing waxes). These waxes eliminate duplicating techniques for the working models and saves time. They are used for all types of metal works, crowns, bridges, implants. After modeling, these waxes can be cured by any standard lab UV or halogen light. These waxes are easy to use, economic, cures quickly, has appreciable strength an elasticity and they are odorless and stable. ${ }^{[15,16]}$

\section{Magnets in Prosthetic Dentistry}

Magnets have generated great interest within dentistry and their application are numerous. The two main areas of their interest are in the field of orthodontics as well as removable prosthodontics. The reason for their popularity is related to their small size and strong attractive forces that allows them to be placed in prosthesis without being obtrusive within the mouth.

The main magnetic materials used is the rare earth elements Neodymium-Iron Boron ( $\mathrm{Nd}, \mathrm{Fe}$, and B). Other materials used include RE Alloy, Samarium-Cobalt $(\mathrm{Sm}-\mathrm{Co})$. Samarium iron nitride is a promising new candidate for permanent magnet application.

Another advancement includes the encapsulation of the pre-existing magnets within a relatively inert alloys such as stainless steel or titanium. ${ }^{[17,18]}$

\section{Implant Systems}

\section{Porous Titanium Foam Implants}

The new porous titanium foam dental implants has been developed at the NRC Industrial Materials Institute (NRC-IMI) in Longueil. Unlike current solid titanium implants, the NRC-IMI material is porous. This provides a site for bone cells to grow into the implant and more solidly anchor it. This new porous yet durable material facilitates the creation of implants in smaller sizes. Its use will avoid the need for the patient to have a bone graft, making the surgery simpler, faster and cheaper.

\section{Clipping implant systems}

This screw-less dental implant system connects implant and supra structure with a novel clipping mechanism. Fatigue of material, resulting in loose or broken screws and unintended malformations, is a possibility. ${ }^{[19]}$

\section{Surface modifications}

Dental implant surfaces are modified by titanium plasma spraying, acid etching, laser sintering or sandblasting. Surface coating with crystalline and amorphous phases of titanium fluorapatite and hydroxyapatite is done to enhance the osseointegration ability of titanium to bone. The titanium implant surface oxide layer modification can be done by anodically oxidising $\mathrm{Ti}$ in a proprietary electrolytic solution resulting in an increased thickness of oxide layer (coronally $1-2 \mu \mathrm{m}$ and apically $10 \mu \mathrm{m}$ ) and a porous surface topography. Bio-chemical modifications of implant surfaces by incorporation of bone morphogenetic proteins and growth factors have done in the intention to enhance the bone formation around the surface of the implant.

One approach for controlling cell-biomaterial interactions utilize cell adhesion molecules. Since identification of the Arg-Gly-Asp (RGD) sequence as a mediator of attachment of cells to several plasma and extra cellular matrix proteins, including fibronectin, vitronectin, Type I collagen, osteopontin and bone sialoprotein, researchers have been depositing RGD - containing peptides on biomaterials to promote cell attachment. Cell surface receptors in the integrin super family recognize the RGD sequence and mediate attachment. [20]

A second approach to biochemical surface modification uses biomolecules with demonstrated osteotropic effects. Many growth factors have been cloned and are recombinantly expressed. They have effects ranging from mitogenicity (e.g., interlukin growth factor-1, FGF-2 and platelet rich plasma to increase activity of bone cells (e.g. Transforming growth factor -1 . (TGF-1) enhances collagen synthesis) to osteoinduction (e.g., bone morphogenetic proteins (BMPs). By delivering one or more of these molecules which normally play 
essential roles in osteogenesis, directly to the tissueimplant interface, it is possible that bone formation may be promoted in implant applications. Platelet rich plasma (PRP), a modification of fibrin glue made from autogenous blood, is being used to deliver growth factors in high concentration to sites where bone formation is needed. Growth factors released from plasma includes platelet derived growth factor (PDGF), transforming growth factor(TGF), platelet derived epidermal growth factor, platelet derived angiogenesis factor, insulin growth factor 1 (IGF-1) and platelet factor. ${ }^{[21]}$

\section{Gingival Retraction Systems}

\section{Expasyl}

It is temporary gingival retraction system. It is an alternate to traditional gingival retraction procedures (gingival retraction cords). It is a painless, fast, reliable and high quality system for temporary opening of sulcus.

Expasyl is aluminum chloride in paste form. Expasyl system separates marginal gingiva from tooth without harming the epithelial attachment. Opening of sulcus does not cause bleeding. The risk of gingival recession or bone resorption that are sequel to damage caused to epithelial attachment is eliminated.

\section{Magic foam cord}

Magic Foam Cord is the expanding PVS material. Magic Foam Cord is a Non-haemostatic gingival retraction system. Designed for easy and fast retraction of the gingival sulcus without the potentially traumatic and time consuming packing of retraction cord. Magic Foam Cord material is syringed around the crown preparation margins and a cap (Comprecap) is placed to reportedly maintain pressure. After five minutes, the cap and foam are removed and the tooth is ready for the final impression.

Advantages are non-traumatic method of temporary gingival retraction, easy and fast application directly to the sulcus without pressure or packing, effortless removal. It contains no hemostatic chemicals that may contaminate the impression

\section{Stayput}

Stay put is so pliable that it stays where you put it. Stay-put is a unique combination of softly braided retraction cord and an ultra fine copper filament which can be easily adapted and can be preformed. It does not lift out of the sulcus, does not unravel, no overlapping is required and it is non-impregnated; but can be impregnated with an astringent or hemostatic solution as required. (22 23)

\section{Ceramics}

Dental Ceramics are non-metallic, inorganic, structures primarily containing compounds of oxygen with one or more metallic or semi-metallic elements. They are characterized by their refractory nature, high hardness, susceptibility to brittle fracture at relatively low stresses and chemical inertness. Recent advances in ceramic materials are In Ceram, Empress, Tech Ceram, Cad/Cam, Procera system, Captek system,

\section{$\underline{\text { In-Ceram }}$}

In-Ceram is supplied as one of the three core materials

1. In Ceram Spinel

2. In Ceram Alumina

3. In Ceram Zirconia.

A slurry of one of these materials is slip cast on a porous refractory die and heated in a furnace to produce a partially sintered coping. The partially sintered core is infiltrated with glass to eliminate porosity and strength slip core. Its fracture toughness is higher than conventional porcelain. In-ceram Spinel is indicated for anterior single unit inlays, on lays, crowns and veneers. In-ceram Alumina is indicated for anterior and posterior crowns and Inceram Zirconia is indicated for posterior crowns and FPD. The collective advantages of all three glassinfiltrated core materials are

1. Lack of metal.

2. Relative high flexural strength and toughness.

3. Ability to be use any luting cement.

\section{Empress}

This ceramic is hot pressed injection molded ceramics. It utilizes the lost wax technique. A Lucite re-enforced glass ceramic is pressed into the mold at 1050 temperature. The increased strength is 
attributed to finely dispersed Lucite crystals, which increase the resistance to crack propagation. ${ }^{[24]}$

Advantages are lack of metal, translucent ceramic core, high flexural strength, Excellent fit and esthetics. Disadvantages are potential for fracture if used in posterior region. Its use is limited to use as a core material for crowns and very short span bridges.

\section{Techcerem}

A thin $(0.1-1.0)$ alumina core base layer is produced using thermal spray technique resulting in a density of 80 to $90 \%$. Optimum strength and translucency are achieved by a sintering process at $1170^{\circ} \mathrm{C}$. The range of base layer thickness makes this technique versatile and appropriate to a range of restoration types. Subsequent reproduction of aesthetics is achieved by the incremental application of a range of specially developed porcelains in the traditional manner

\section{CAD/CAM}

Computer aided designing and computer aided manufacturing (CAD/CAM) technology in dentistry is increasing, both in the dental laboratory and general practice settings, to fabricate all-ceramic inlays, onlays, crowns, and veneers. Only one CAD/ CAM system that is available for in-office chair side use, namely CEREC ${ }^{\circledR}$ 3D. A digital image is captured of the tooth preparation. This image contains three dimensional information regarding size of the tooth and defect being restored. The restoration is designed in the computer. A tooth colored block of ceramic or composite is then used to machine the restoration.

Improvements to the original system include new software, the introduction of finer grained porcelain blocks to reduce oppositional wear, a wider range of preformed ceramic block shades and conversion to an electric turbine with better cutting control for greater fitting accuracy. The newer milling systems include the use of the blocks in gradient form to mimic the translucency of the tooth structure. All the blocks which are being used in the recent past are bar coded, that holds the information of the block used with the CAD data, which would enable the technician to fabricate a similar restoration, in case of clinical failure of a restoration. ${ }^{[25,26]}$

\section{Procera System}

These all-ceramic individual restorations comprise a densely sintered alumina core. It contains 99.9\% alumina and it the hardest among ceramics used. It can be used for anterior, posterior crowns, veneers, onlays and inlays. ${ }^{[27,28,29]}$

\section{Captek System}

Captek is acronym for capillary casting technology. An alternative methodology for elimination of the casting process from metal-bonded crowns and bridges. This technique involves the adaptation of a wax strip, impregnated with a gold platinumpalladium powdered alloy, to a refractory die. Firing produces a rigid porous layer which is then in filled with gold from a second wax strip by capillary action. The finalized metal coping is then veneered with porcelain. The advantages of this system are said to include improved marginal fit (attributed to use of the capillary cast, rather than the lost wax technique) and enhanced aesthetics and biocompatibility. ${ }^{[30]}$

\section{Recent Core Materials and Technologies}

The most recent core materials for all-ceramic FPDs are the yttrium tetragonal Y-TZP-based materials. Y-TZP-based materials were initially introduced for biomedical use in orthopedics for total hip replacement and were highly successful because of the material's excellent mechanical properties and biocompatibility. In the early 1990s, the use of Y-TZP expanded into dentistry (endodontic posts and implant abutments) and Y-TZP is currently being evaluated as an alternative core material for full-coverage restorations such as all-ceramic crowns and all-ceramic FPDs.

Yttrium oxide is a stabilizing oxide added to pure zirconia to stabilize it at room temperature and to generate a multi phase material known as partially stabilized zirconia. The exceptional mechanical properties of YTZP (high initial strength and fracture toughness) are due to the unique physical property of partially stabilized zirconia. Tensile stresses acting at the crack tip induce a transformation of the metastable tetragonal zirconium oxide form into the monoclinic form.

This transformation is associated with a local increase of $3 \%$ to $5 \%$ in volume. This increase in volume results in localized compressive stresses 
being generated around and at the tip of the crack that counteract the external tensile stresses acting on the fracture tip. This physical property is known as transformation toughening.

Because of their material-inherent advantages, Y-TZP-based all-ceramic restorative systems may allow prosthodontists to use traditional clinical procedures similar to those used in the fabrication of metal-ceramic restorations in terms of preparation design and cementation procedures. With Y-TZPbased systems that use a CAD/CAM technology, ceramists use new techniques and technologies in addition to traditional ones. Such new technologies may allow the production of consistent highquality $\mathrm{Y}-\mathrm{TZP}$ frameworks in terms of design and fabrication, strength, fracture toughness, and stresscorrosion resistance.

They are esthetic, have clinically acceptable marginal fit, and allow the ceramist to use traditional veneering procedures with the compatible esthetic porcelain. In addition, such systems may prove to be simple to handle and less technique sensitive from a clinical standpoint while providing patients with esthetic and functional restorations.

The long-term results of these studies are paramount to the assessment of their long-term success and for the establishment of more specific guidelines for proper patient selection that will ensure long-term predictable esthetic and functional success. ${ }^{[31,32]}$

\section{Impression Materials}

Alginate is the most commonly used impression material and has the advantages such as quick setting time, low cost, and mild flavor. But it has considerable disadvantages like poor dimensional stability, messy, hazardous dust, and needs repetitive hand mixing.

\section{Dustless Alginate}

To overcome these disadvantages various modifications have been done like dustless Alginate which Contain high algin content. Glycerin is incorporated on alginate particles. The high align content provides for a quality impression without the excessive flow.

\section{Fluoride containing alginate}

Addition of $\mathrm{NaF}$ or $\mathrm{SnF} 2$ in an alginate impression material may result in effective release of fluoride without deteriorating the properties of material itself. Fluoride-containing dental alginate impression materials can exert a considerable reduction in enamel solubility

\section{Chromatic Alginate}

This alginate provides rapid processing and setting times. It has improved compatibility with plaster of paris. It is thixotropic, does not drip and only flows when pressure is exerted during the impression procedure. It is also uniform, smoother and the compact surface enables a higher definition of detail. Three-phases of chromatic alginate are as follows: Purple phase denotes mixing time, orange phase denotes processing time and the yellow phase indicates insertion into the mouth.

\section{Auto-Mix Alginate}

AlgiNot is a time-saving, cost-effective alternative to traditional alginate. It is not hand mixed, improving the handling characteristics. Thus it saves time. This material is not affected by the disinfectant, thus infection control is assured.

\section{$\underline{\text { Silgimix }}$}

This is an alginate replacement impression material. Silgimix is developed from vinyl polysiloxane chemistry. It addresses the shortcomings of alginate materials by giving users the ability to disinfect, the option of pouring multiple times and the ability to scan the impression electronically.

Rubber based impression materials are nonaqueous impression materials. The most widely used rubber based impression material is polyvinyl siloxane (PVS). This widespread use is attributed to its dimensional stability, ease of handling, excellent elastic recovery, good detail reproduction, ability to pour multiple casts from single impression. A significant limitation of PVS is its hydrophobicity. This causes difficulty in impression making procedure in presence of blood and saliva and also during pouring a cast. To overcome this limitation hydrophilic polyvinyl siloxane has been introduced. 


\section{Hydrophilic Polyvinyl Siloxane}

To improve hydrophilic properties, surfactant and hydrophilic monomer are added which result in a truly low contact angle. A lower contact angle measure means greater "wettability", displacing oral fluids for a more detailed impression. These additives also increase surface energy within the material, and therefore increase detailed reproductions, even in the presence of blood and saliva. However, addition of surfactants makes the preparation of electroformed dies more difficult as the metallizing powder does not adhere well to the surface of hydrophilic addition silicone. ${ }^{[33]}$

\section{Vinyl Poly ether Silicone}

Yet another effort to improve the mechanical and physical properties of the elastomer is the introduction of Vinyl Poly Ether Silicone which is a hybrid of poly-vinyl siloxane and polyether. This material is made hydrophilic and relatively rigid by virtue of the polyether component and the properties of flow and detail reproduction is offered by polyvinyl siloxane.

This material is available in light body, monophase and heavy body consistencies which can be used in a single step technique, double step technique and putty wash technique. It is claimed that there may be a possible loss of detail reproduction if the material in incompletely mixed. Although the manufacturers claim mechanical and physical properties superior to other elastomers, further studies are required to substantiate the evidence. ${ }^{[34]}$

\section{Nano-filled Poly vinyl Siloxane}

Nano-fillers are integrated in poly vinyl siloxane impression material It has improved hydrophilic properties, better flow, enhanced detail and precision. The newest class of elastomeric impression materials is a vinyl-polyether hybrid material called SENN.

SENN combines properties from addition silicone and polyether impression materials. It is a polymer with polyether and siloxane (addition silicone) groups. With the polyether groups, a hydrophilic material is produced without the use of a surfactant.
With the siloxane groups on the polymer chain, a material that is dimensionally stable and has good recovery from deformation is combined with hydrophilic properties that the polyether groups produce. SENN has a platinum catalyst. The tear strength is a little low, but the wetting properties of SENN are good. It is supplied as a putty - heavy, medium, and wash materials - in either a fast or regular set material. These hybrid materials have the intrinsic hydrophilicity necessary to improve impression making by wetting a tooth and allowing easy pouring for cast fabrication. ${ }^{[35]}$

\section{Maxillofacial Prosthesis Materials ${ }^{[36,37]}$}

These biomaterials are developed to fabricate restorations of acquired or congenital maxillofacial defects. The polymethyl methacrylate resins are gold standard for rehabilitations intraorally. The extra oral defects need restorations which not only closes the defect but also resist the ravages of time, temperature and other mechanical and physical properties such as dimensional stability, colour stability etc. A few of the recently evolved maxillofacial materials have been discussed below, which has stood the test of time.

\section{Isophorone Polyurethane}

A unique polyurethane elastomers based on a cycloaliphatic di isocyanate monomer is being developed and tested. The material is formulated as a three-component kit comprising an isocyanateterminated prepolymer, a triol as the cross-linking agent, and an organotin catalyst. The elastomers have unusually high strength compared to other aliphatic polyurethanes. This is due to cycloaliphatic isopherone moiety in the vulcanized network. The aliphatic nature of the polymer improves resistance to the sunlight degradation common to aromatic polyurethanes. The system is not hazardous to the prosthodontist or the patient.

\section{$\underline{S E-4524 U}$}

This silicone is representative of family of polymers that require moderate to high temperatures for the initiation of the cross-linking reaction.

The Silastics 44514 and 44515 available from Dow Corning are of the same general type. General Electronic provides the $\mathrm{SE}-4524 \mathrm{U}$ material in the 
form of unprocessed gum stock, with or without incorporated catalyst. The vulcanization reaction involves the combination of methyl groups on the polymer chains. An organic peroxide is used to initiate the cross-linking reaction.

With this material, the prostheses must be fabricated at a temperature high enough to cause decomposition of the peroxide catalyst.

\section{$\underline{\text { PDM Siloxane }}$}

It is a type of HTV silicone that has physical and mechanical properties that exceeded values considered clinically acceptable.

\section{$O 7-4635, Q 7-4650, Q 7-4735, S E-4524 U$}

These are new generation of HTV silicones, which have improved mechanical and physical properties. The processing characteristics of Q7-4635 and SE4524U were particularly favorable because of their single component system with unlimited shelf life.

\section{$\underline{M D X 4-4210}$}

Because of remarkable improvements over the older Silastic polymers, this material has become increasingly popular in the maxillofacial clinics. The elastomer is based primarily on a modified poly dimethyl siloxane (PDMS) structure, and the vulcanization mechanism involves the addition of $\mathrm{Si}-\mathrm{H}$ groups to Si-vinyl units. A platinum catalyst initiates the cross-linking reaction; the curing reaction is sensitive to any contaminant which is capable of coordination with the platinum catalyst. Amines, sulfur and tin compounds are especially troublesome and inhibit the cure of the material.

\section{$\underline{A-2186}$}

It is a recently developed material whole physical and mechanical properties are inferior compared to MDX 4-4210.

\section{Conclusion}

Although, marked breakthrough in technology and recent advancements in biomaterials present with a massive assortment of materials and techniques, it is ultimately the job of the practicing dentist to choose the materials to suit the biological, functional and esthetic requirements of the restorations and replacements in the complex oral environment.

It is mandatary that clinicians should be updated about various biomaterials and their manipulative characteristics and technical considerations which would enable them to render quality care for patients.

\section{References}

1. Prashanti E, Jain N, Shenoy VK, Reddy JM, Shetty B T, Saldanha S. Flexible dentures: A flexible option to treat edentulous patients. Journal of Nepal dental association 2010; 11: 85-7.

2. Yannikakis S, Zissis A, Polyzois G, Andreopoulos A. Evaluation of porosity in microwave-processed acrylic resin using a photographic method. J Prosthet Dent 2002; 87: 613-9.

3. Levin B, Sanders JL, Reitz PV. The use of microwave energy for processing acrylic resins. J Prosthet Dent 1989; 61:38185.

4. Yadav NS, Elkawash H. Flexural strength of denture base resin reinforced with aluminum oxide and processed by different processing techniques. J Adv Dental Research 2011; 26: 214-19.

5. John J, Gangadhar SA, Shah I. Flexural strength of heatpolymerized polymethyl methacrylate denture resin reinforced with glass, aramid, or nylon fibers. J Prosthet Dent 2001; 86:424-27

6. Franklin P, Wood DJ, Bubb NL. Reinforcement of poly (methyl methacrylate) denture base with glass flake. Dent Mater 2005; 21:365-70.

7. Puri G, Berzins DW, Dhuru VB, Raj PA, Rambhia SK, Gunjan Dhir, Dentino AR, Effect of phosphate group addition on the properties of denture base resins. J Prosthet Dent 2008; 100: 302-08.

8. Vuorinen AM, Dyer SR, Lassila LVJ, Vallittu PK. Effect of rigid rod polymer filler on mechanical properties of polymethyl methacrylate denture base material. Dent Mater 2008; 24: 708-13.

9. Cheng Y, Sakai T, Moroi R, Nakagawa M, Sakai H Selfcleaning Ability of a Photo catalyst-containing Denture Base Material. Dent Mater 2008; 27: 179-86.

10. Suzuki S. In vitro wear of nano-composite denture teeth. Int J Prosthodont. 2004; 13(4):238-43.

11. Low D, Mori T. Titanium full crown casting: thermal expansion of investments and crowns accuracy. Dent Mater 1999; 15:185-90.

12. Hung CC, Hou GC, Tsai CC. Pure titanium casting into zirconia-modified magnesia-based investment molds. Dent Mater 2004; 20: 846-51.

13. Paulino SM, Leal BC, Pagnano VO, Bezzon OL. The castability of pure titanium compared with $\mathrm{Ni}-\mathrm{Cr}$ and $\mathrm{Ni}-$ Cr-Be alloys. J Prosthet Dent 2007; 98: 445-54.

14. Ellingsen JE, Johansson CB, Wennerberg A, Holmen A. Improved retention and bone to implant contact with fluoride modified titanium implants. Int J Oral Maxillofac Implants 2004; 19: 659-66.

15. William J.O'brein: Dental Materials and their selection: Quintessence Publishing Co., 3rd edition; 1985. 
16. Kenneth J. Anusavice. Philips' Science of dental Materials, W.B. Saunders Company; A division of Harcourt Brace \& Company, 11th edition,1999.

17. Highton R, Caputo AA, Pezzoli M, Matyas J. Retentive characteristics of different magnetic systems for dental applications. J Prosthet Dent 1986;56:104-6.

18. Riley MA, Walmsley AD, Harris IR. Magnets in prosthetic dentistry. J Prosthet Dent 2001; 86:137-42.

19. Tomas A, Wennerberg A. Oral implant surface: part 2 review focusing on clinical knowledge of different surfaces. Int J Prosthodont 2004; 17: 544-64.

20. John B. Brunski. Biomaterials and Biomechanics of Oral and Maxillofacial Implants: Current Status and Future Developments. Int J Oral Maxillofac Implants 2000;15: 1546.

21. G. Ajay kumar. Recent Advances in Dental Implantology. Journal of Dental and Medical Sciences 2012;3: 28-30.

22. Ferrari M, Cagidiaco MC, Ercoli C. Tissue management with a new gingival retraction material: a preliminary clinical report. J Prosthet Dent 1996: 75; 242-47.

23. Bowles WH, Tardy SJ, Vahadi A. Evaluation of new gingival retraction agents. J Dent Res 1991; 70: 1447-52.

24. Rouse JS. Use of heat-pressed leucite reinforced porcelain in "difficult" veneer cases: A clinical report. J Prosthet Dent 1996; 76(5): 461-63.

25. Dianne Rekow. Dental CAD CAM Systems. State of the art. J Am Dent Assoc 1991;122: 43-48.

26. Werner H Mormann, Andreas Bindel. All ceramic, chairside computer aided dental restoration. Dent Clin N Am 2002: 46; 405-26.

27. Brunton PA, Smith P, Mc Cord JF, Willson NH. Procera allceramic crowns: a new approach to an old problem? Br Dent J 1999;186: 430 - 34 .
28. Anusavice K J. Recent developments in restorative dental ceramics. J Am Dent Assoc 1993; 124: 72-84.

29. Jason AG. Recent advances in materials for all-ceramic restorations. Dent clin N Am 2007: 51; 713-27.

30. Rizkalla AS, Jones DW. Indentation fracture toughness and dynamic elastic moduli for commercial feldspathic dental porcelain materials. Dent Mater 2004; 20:198-206.

31. Luthardt RG, Holzhuter MS, Rudolph H, et al. CAD/ CAM-machining effects on Y-TZP zirconia. Dent Mater 2004;20:655-662.

32. Giordano R, Morgano S, Papanagiotou H, and Pober R. Invitro evaluation of low temperature aging effects and finishing procedures on the flexural strength and structural stability of Y-TZP dental ceramics. J Prosthet Dent 2006; 96:154-64.

33. Shetty R M, Bhander G R, Mehtha D. Vinyl polysiloxane ether - A breakthrough in Elastomeric impression material. World journal of dentistry 2014; 5(2): 134-37.

34. Johnson GH, Chellis KD, Gordon GE, lepe X. Dimensional stability and detail reproduction of irreversible hydrocolloid and elastomeric impression disinfected by immersion. J Prosthet Dent 1998; 79: 446-53.

35. Wadhwani CP, Johnson GH, Lepe X, Wataha JC. Accuracy of reformulated fast set vinyl poly siloxane impression material using dual arch trays. J Prosthet Dent 2009; 101 : 332-41.

36. Woofaardt JF, Chandler HD, Smith BA. Mechanical properties of a new facial prosthetic material.J Prosthet Dent 1985; 53: 228-36.

37. John F Lontz. State of the art material used for maxillofacial prosthetic reconcstruction. Dent Clin N Am 1990: 34; 2-14. 